\title{
Building a Common Culture of IP?
}

\author{
Michel Vivant
}

Published online: 20 April 2016

(C) Max Planck Institute for Innovation and Competition, Munich 2016

We live in a world full of contradictions. Intellectual property is triumphant and at the same time has never been so strongly attacked. IP must be thought of as a global tool where the principle of territoriality remains dominant. On a European level we try to build a common IP law when we are dealing with Grexit or Brexit and a form of breakup of the European Union.

While the trans-border dimension of the subject is unavoidable, even in the European context, it is not certain that needs and the philosophies are the same in Berlin, Paris, London, Stockholm and Valetta. We build, we try to build something, but sometimes it seems that we do so without a plan, based on the sole efficiency of the lobbies.

Developing a coherent IP system built on a solid basis and commonly shared is not an easy task. Discourses are too often simplistic: IP which fosters innovation and consequently progress, versus IP which creates artificially secure incomes against the public interest. Lawyers favour a "technical" (i.e. purely legal) discourse (What is a man skilled in the art? What does originality mean based on case law?) and, when the opportunity is given to reflect on a right, too often they prefer to return to such a technical discourse. ECJ case law regarding the functions of trademarks is a very good example of this. The dominant comments are pragmatic - what does this case law allow? - which is perfectly legitimate but a bit "short". Of course there are papers that question the legitimacy of such an approach. But, in my view, it would have been preferable to question on this occasion not (in a highly academic way) what a trademark is, but what we want to do with trademarks. While this kind of question has been asked by various authors, it remains all too rare.

\footnotetext{
M. Vivant $(\bowtie)$

Full professor at Sciences Po; Academic Director of the intellectual property program of the master's in Droit économique; Doctor honoris causa, University of Heidelberg, Paris, France e-mail: mvivant@aol.com
} 
And yet if we want to build an IP system which is

- relevant

- effective

- and legitimate

we must take this path - and more importantly we must seek to build a model which is, if not global, at least regional, i.e. in our case, European (a global model is conceivable and TRIPS can be seen as an example of such globalization, but is TRIPS so really global and, on the other hand, is it possible to consider that the same rules are relevant for Paris and Dakar, for Washington and Guatemala?).

I am deeply convinced that we have to question what our objective is when we recognize a copyright, a patent, a trademark or any other IP right, and we must consider this question as open.

In other words, we must not be satisfied with what we know, considering that it is an expression of the truth! The example of this kind of silly "war" between copyright and droit d'auteur (author's rights) perfectly illustrates that nothing comes of such a view. In too many cases, it is a battle of caricature(s) against caricature(s). Let us take the example of the moral right. For many copyright lawyers, it is difficult to imagine a more absurd kind of right! For many authors' rights lawyers it is the indisputable seal of good legislation, protecting the author! But, if we look at the German roots of the institution and more precisely the writings of Kant ("Was ist ein Buch?" [What Is a Book?]), it is clear that we are very far from some extravagant contemporary writings. The theory of Kant was written about philosophy books and, while the pertinence of his ideas can be debated, it is certain that they cannot seriously apply when the work is a bag or a bolt! We may defend the idea that the author must be taken into consideration (and for instance more than in US law) but the "consecration" of the author, according to the title of a French book ("Le sacre de l'auteur"), is something else and, in my opinion, a nonsense.

We have to consider the functions assigned to an IP right. Assigned: in my view, this means that there are no "natural" functions which exist "inherently". We have to consider the functions commonly assigned to an IP right but also the purposes that we actually want to achieve in a given context, taking into account the complexity of those rights which can never been reduced to a single aim. The exercise is very political, obviously in the Aristotelian meaning of this word. To give a sole example, it is common to say that a patent is an incentive to research that is likely to boost development. But we do not have to show a perfect deference for this tool as unquestionable. We have to assess when it is and when it is not an incentive, and we must not forget that patents are also a question of public interest and notably of public health.

If an IP right allocates a market segment to the right holder by means of an (intellectual) enclosure, the question is to know where the "boundary line" must be drawn and the answer, considering fundamental freedoms and competition law: along lines which are strictly necessary. This is an answer that gives rise to further questions... but it is also a guideline that allows us to exonerate ourselves from a "ready-made" answer. 
I would like to concretize this idea through two examples.

The exception panorama is today debated in the copyright field. Is it legitimate? Does it go too far? Does it respect the legitimate rights of the right holder? If we believe that the right holder can prohibit any kind of reproduction or communication, everything has been said! But if we observe that it is absolutely impossible to take photographs of Piccadilly Circus, to shoot a film in the street or in a flat, to draw comic strips with a minimum of realism, without reproducing numerous works: posters, paintings, cars, furniture, dresses, jewels... for me, it seems unthinkable to give the right holder the power to prohibit all these kinds of reproduction. It is not a question of English or German or French tradition. It is the only reasonable answer we can give if we want to avoid turning the copyright into a tool against creativity and creative activity. Furthermore, these observations plead for a wider exception, not limited to the panorama. Next we have very concrete and difficult problems regarding implementation, in particular if we consider the Internet. We have to deal with them. But, if we agree on the principle, doing that, we can also seek to establish where the adequate boundary line should be drawn.

We also have a question of borders, this time intellectual and political ones, with the new Regulation concerning EU trademarks which provides that the owner of a trademark can

prevent all third parties from bringing goods [...] into the Union without being released for free circulation there, where such goods, including packaging, come from third countries and bear without authorisation a trade mark which is identical with the EU trade mark registered in respect of such goods, or which cannot be distinguished in its essential aspects from that trade mark.

So a rightholder can sue a third party even when the protected market is not affected by his/her behaviour. (It can be noted, as it has been already, that it is perhaps contradictory to the international principles of free circulation of goods, but that is not my intention here.) The same observation can be made about the French provisions when the IP Code incriminates, as an infringement, the exportation of marked, patented or copyrighted items. In this case, the French market is not affected. However it is possible to see in these provisions clues for a new understanding of what infringement is in a global context: maybe actions which are still defined by a national (or regional) act but which are grasped as intrinsically reprehensible or at least reprehensible without direct reference to a market especially affected. We can analyse this from a purely technical point of view. We can also find in these provisions the expression of what I call a new understanding and, in this case, we have to examine whether or not, from a European point of view, it is a satisfactory approach. Regardless of my opinion.

I have tried to show that, if we want to build a common approach, a common culture of IP, we will not achieve this by glossing over the texts and looking backwards (even though we do have to respect our own different traditions). We will do so by trying to identify our needs, our desires, economically, philosophically and politically speaking. On the basis of the idea "challenge and response" (the same challenges lead to the same kinds of answers), I believe that it is not an impossible mission but, quite the opposite, a good trail. 